\title{
Exploring Mars with Returned Samples
}

\author{
Monica M. Grady ${ }^{1}$ (D)
}

Received: 5 November 2019 / Accepted: 17 April 2020 / Published online: 6 May 2020

(C) The Author(s) 2020

\begin{abstract}
The international Mars Exploration community has been planning to return samples from Mars for many years; the next decade should see the plans becoming a reality. Mars Sample Return (MSR) requires a series of missions, first to collect the samples, then to return them to Earth, whilst preventing the contamination of both Earth and Mars. The first mission in the campaign, Mars 2020, will land at Jezero Crater in early 2021; samples should return to Earth sometime after 2032. The information to be derived from analysis of martian samples in terrestrial laboratories equipped with state-of-the-art instrumentation is more than recompense for the difficulties of the MSR campaign. Results from analyses of returned samples will enable increased understanding of martian geological (and possibly biological) evolution. They will facilitate preparations for human exploration of Mars and by providing a second set of absolute ages for a planetary surface will validate (or otherwise) application of the lunar crater-age scale throughout the Solar System.
\end{abstract}

Keywords Mars-sample-return $\cdot$ MSR $\cdot$ Mars $\cdot$ Jezero

\section{Introduction}

Ever since the Mariner 9 mission of 1971-2 returned images of the martian landscape showing networks of craters, dried-up river valleys and towering (but extinct) volcanoes (Mutch and Saunders 1976), it has been known that Mars experienced impact, fluvial, volcanic and aeolian processes - and a potential for martian life to develop. Knowledge of the extent and complexity of these processes has increased in detail with each succeeding space mission. We now have global scale coverage of the planet at visible wavelengths and almost

Role of Sample Return in Addressing Major Questions in Planetary Sciences

Edited by Mahesh Anand, Sara Russell, Yangting Lin, Meenakshi Wadhwa, Kuljeet Kaur Marhas and Shogo Tachibana

$凶$ M.M. Grady

monica.grady@open.ac.uk

1 School of Physical Sciences, The Open University, Milton Keynes MK7 6AA, UK 
(a)

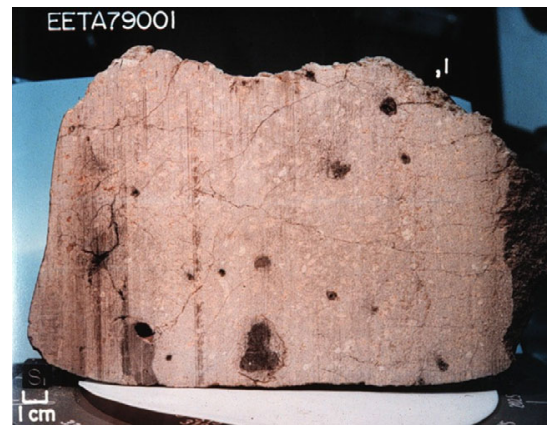

(b)

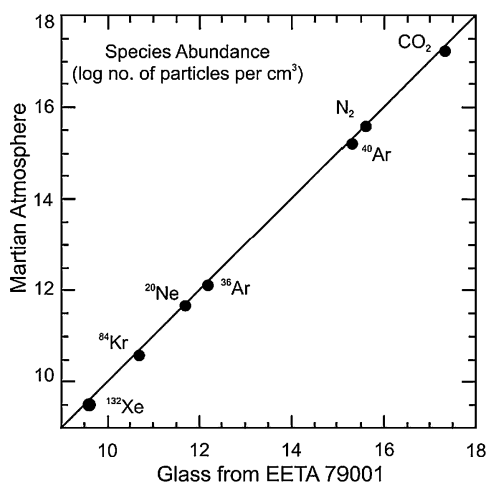

Fig. 1 (a) The EETA 79001 meteorite, showing areas of black glass on its cut-surface (image credit NASA-JSC); (b) Compositional evidence that gas trapped inside EETA 79001 has the same composition as Mars' atmosphere (reproduced from Pepin 1985)

total coverage in the infrared. We know the distribution of craters across the planet's surface, the location of the main volcanic regions, the existence of a complex network of fluvial features and the composition and dynamic properties of the atmosphere. This has given us a broad idea of Mars' evolutionary history based on a relative chronology that ties together the different processes (Tanaka 1986). Changes in mineralogy brought about by aqueous alteration have been observed from orbit and at the landing sites of the Spirit, Opportunity and Curiosity rovers (e.g., Ehlmann and Edwards 2014; Ruff and Farmer 2016; Bedford et al. 2019). These changes, when related to a cratering chronology, can be modelled to yield information about the timing, extent and duration of fluid flow, as well as constraining the temperature and composition of the fluid (e.g., Griffith and Shock 1997; Ehlmann et al. 2011; Bridges et al. 2015; Zolotov and Mironenko 2016).

Complementary information about Mars is obtained from martian meteorites, a group that has been recognised since the Antarctic meteorite Elephant Moraine (EETA) 79001 was found to contain pockets of clear black glass in which gas with the composition of Mars' atmosphere was trapped (Bogard and Johnson 1983; Becker and Pepin 1984; Pepin 1985 and Fig. 1).

It was inferred that EETA 79001 had been ejected from Mars during an impact cratering event. Once this suggestion was accepted, analysis of oxygen isotopic composition indicated that other igneous meteorites with young crystallisation ages had the same source (Clayton and Mayeda 1983; Franchi et al. 1999). Since then, the number of samples of Mars has grown to over 240 - although the number of individual meteorites is unknown because of the difficulty of matching samples that fragmented prior to collection. The Meteorite Database at https://www.lpi.usra.edu/meteor/metbull.php provides regular updates of this figure. Differences in mineralogy and mineral chemistry imply that they represent at least nine different rock types coming from a number of discrete impact events from different regions of the planet (Righter 2017). Unfortunately, whilst comparisons can be made between the compositions of the Martian meteorites (as measured in a laboratory) and composition of Mars (as measured by orbiting and landed craft), it is not possible to determine the specific region of Mars from which any of the meteorites has been derived (Werner et al. 2014). Thus, their utility in addressing questions regarding the origin and evolution of Mars has limitations. In addition, the meteorites are all igneous rocks (apart from the breccia NWA 7034 and its 
pairs) so their ability to record evidence of martian biological activity in a hydrous sedimentary context is limited. Admittedly, several of the samples (particularly the nakhlites and the orthopyroxenite ALH 84001) contain assemblages of secondary minerals (combinations of phyllosilicates, carbonates, halite, etc.) produced by water on Mars (e.g., Bridges et al. 2001; Melwani Daswani et al. 2016; Lee et al. 2018) infiltrating fractures and which have the potential to harbour traces of life, but to date, no such traces have been definitively recognised (McKay et al. 1996; Steele et al. 2007).

There are, then, three highly complementary and detailed sets of data from which information about Mars may be inferred. Images and spectral information from orbiting spacecraft have provided global coverage of landforms and associated mineralogical variations. This has allowed a relative chronology for fluvial and volcanic activity to be established. Information obtained by instruments on rovers and landers have enabled much more detailed investigation of smaller, more specific areas on the planet. Finally, the absolute ages of meteorites ejected from Mars during impacts has helped to constrain the timing of periods of volcanic activity and aqueous alteration. Measurement of the elemental and isotopic composition of secondary minerals have informed models of fluid flow and water-rock ratios to illustrate how different generations of alteration relate to each other (Melwani Daswani et al. 2016).

Despite all this information and the insight it has given to Mars' evolutionary history, each dataset is lacking in some way, such that we cannot yet construct a complete (absolute) timeline for Mars. Data from orbiting spacecraft define a relative chronology and give context to data from rovers and landers. Data from rovers and landers provide more detailed chemical and mineralogical compositions to refine global stratigraphy whilst martian meteorites provide absolute ages and detailed compositional data for specific phases but without any contextual information. The most logical next step to increase knowledge about Mars is to bring samples from known locations back to Earth for analysis.

Return of samples from the surface of Mars has been a goal of the international Mars exploration community for many years. There has been much discussion of the profile of a sample return mission, including comparison with the return of the Apollo 11 samples from the Moon. Almost as soon as Armstrong set foot on the lunar surface, he collected a 'contingency sample'. This comprised a few scoops of lunar regolith from close to the lander (Kramer et al. 1977). The idea behind the collection was that if things became non-nominal (i.e., went wrong) and the astronauts had to leave the lunar surface rapidly, they would at least have some material to bring back. Following that example, the utility of a 'grab and go' mission to Mars has been considered. However, as understanding of the interplay between different reservoirs (atmosphere, hydrosphere-cryosphere and lithosphere) has increased and realisation of the potential habitability of Mars has grown, it has become clear that return of a 'grab and go' (i.e., randomly-collected) sample would be insufficient to answer the major questions of interest about Mars, viz the absolute age of the bedrocks and the potential for life in the subsurface (Beaty et al. 2019). The most recent iteration of a Mars Sample Return mission is described below.

\section{The Pros and Cons of Ex Situ Versus in Situ Analysis of Martian Samples}

There are (at least) four advantages to analysing a sample back on Earth (ex situ) compared with making analogous measurements on Mars (in situ). There are also several disadvantages to removing a sample for measurement elsewhere. We will consider the advantages 
of sample return first. In doing so, we make the assumption, just as is recommended in the iMOST report (Beaty et al. 2019), that suites of samples are collected from a locality rather than single specimens. It is also assumed that appropriate instrumentation is available and operational.

\subsection{Advantages of Ex Situ Analysis}

(i) Sample preparation techniques: a major advantage of analysis of returned samples compared with analysis of a sample in situ on Mars' surface is that more sophisticated sample preparation techniques can be employed to obtain high quality and high precision information. One of the most widely-applied techniques in geological investigations is to make a polished section from a rock sample. A single chip of rock with dimensions of less than $2 \times 2 \times 2 \mathrm{~mm}$, once embedded in resin, can be sliced to produce several sections or mounts. An entire panoply of measurements can be made on a single polished mount at high spatial resolution revealing details that are invisible at lower magnifications. A polished mount is suitable for analysis by electron microscopy to determine the major and minor element compositions of specific minerals, the texture, grain size and luminescence properties of the rock, its alteration by fluids and its structure and shock history. The mount would also be available for examination by other microbeam techniques, including electron microprobe (for trace elements) and ion probe (for elemental and isotopic compositions). Similarly, spectroscopy (across infrared, visible and ultraviolet wavelengths and Raman) could be performed on a polished mount to obtain structural and organic information. Other important preparation techniques are possible in a terrestrial laboratory that cannot (as yet) be performed on Mars' surface. For example, the picking of individual, specific mineral grains from a specimen, followed by dissolution of the grains in a series of acids for age-dating. Or processing of solid materials through sequential solvent and acid extractions and derivatisation for the analysis of organic molecules. Although the SAM instrument suite on Curiosity is able to perform some wet chemistry experiments, including derivatisation (Freissinet et al. 2015), it is only carrying a very limited number and amount of chemicals. This precludes the more sophisticated analyses carried out in organic chemistry laboratories on Earth, where different 'recipes' for extractions can be substituted if appropriate.

(ii) Range of analytical techniques and instruments: another of the major advantages of having samples returned to Earth is the range of analytical techniques that can be applied to them. All missions are restricted in terms of payload: factors such as cost, mass, volume, power requirements and data transfer (bandwidth) limits constrain choices of instruments and place limits on the ensemble of measurements that can be made by any specific mission. Additionally, although instruments onboard rovers are now capable of determining the mineralogy, mineral chemistry, volatile elemental and isotopic compositions of rocks and soil on the surface of Mars, there are still gaps where information is missing because analytical techniques have not yet been adapted or developed for deployment on spacecraft. For example, a CT scanner is a large piece of equipment that is becoming almost a 'workhorse' instrument to produce 3-D images of rocks, showing texture, porosity and composition. If attached to a synchrotron source, the measurements can be at very fine-scales on samples as small as individual grains. It is unlikely, in the foreseeable future, that such an instrument could be miniaturised for deployment on Mars. 
(iii) Responsive investigation pathways: A further advantage of laboratory analysis is that investigation pathways are responsive to each discovery. Measurements using different techniques on a single aliquot of material (which might be chip, powder, polished mount, separated minerals, etc.) can run in sequence and be designed so that one technique does not interfere with results expected from a technique to be applied subsequently. Measurements can be repeated (by the same or different analysts) for internal checking and calibration. Whilst planning of an analytical sequence is essential to get the best possible results from a limited amount of material, because the measurements are taking place in 'real time' (i.e., not autonomously on a planetary surface where instructions must be uploaded ahead of time), changes to a sequence can be made if unusual results are produced from one technique that might require verification from a different point on the analysis pathway. Finally, the repeatability of critical measurements is readily achievable by inter-laboratory comparisons on Earth, but is impractical on Mars.

(iv) Spatial and spectral resolution: Instruments on orbiting spacecraft are generally returning data acquired at low magnification or relatively low spectral and spatial resolution from large areas of the martian surface. The instruments are constrained by limited power availability, mapping geometry, data storage capacity and bandwidth and communication timelines. Although a vast library of information has resulted from orbiting missions, there are gaps where the footprint of the instrument is on a larger-scale than the features being mapped. For instance, one of the outstanding questions about Mars' changing climate is the extent and duration of fluid flow on the surface. The distribution of clay minerals (and other alteration products) is of critical importance in trying to establish the temperature and timing of different fluvial events (e.g., Bishop et al. 2008; Carter et al. 2013), yet differentiation between phyllosilicate species is not always possible from orbit (Ehlmann and Edwards 2014). Similarly, taking a closer view of process-related and diagnostic textural associations using rover-based instruments may show discrepancies between orbital and surface results if there is a much greater variety of minerals present at a site than can be detected from orbit (e.g., Mangold et al. 2017; Rampe et al. 2018). There are definitive analyses (e.g., mineral crystal structure determination by X-ray diffraction) that could be performed on the surface, but appropriate instrumentation has rarely been deployed, thus limiting the intercomparability of results among multiple surface-mission operation areas (Velbel 2018). Laboratory-based equipment can be employed to make measurements at finer spatial scales and get more accurate results for the individual proportions and compositions of minerals present in a mixture of components. As well as gaining information on the source regions for the different minerals, leading to understanding of the environment in which the rock formed, results can be used to calibrate orbital measurements so that the occurrence of the same compositional mixture can be mapped across the surface with greater confidence.

\subsection{Disadvantages of Ex Situ Analysis}

The disadvantages of removing a sample from its environment prior to analysis revolve around changes that might occur because the sample is no longer in thermal or redox equilibrium with its surroundings. Before the material arrives back on Earth, it will have spent at least 10 years encapsulated within sample tubes. For part of that time, the tubes will be on Mars' surface experiencing diurnal and annual thermal cycling that might differ from the cycles the samples experienced when in situ. This has the potential to alter the samples, which 


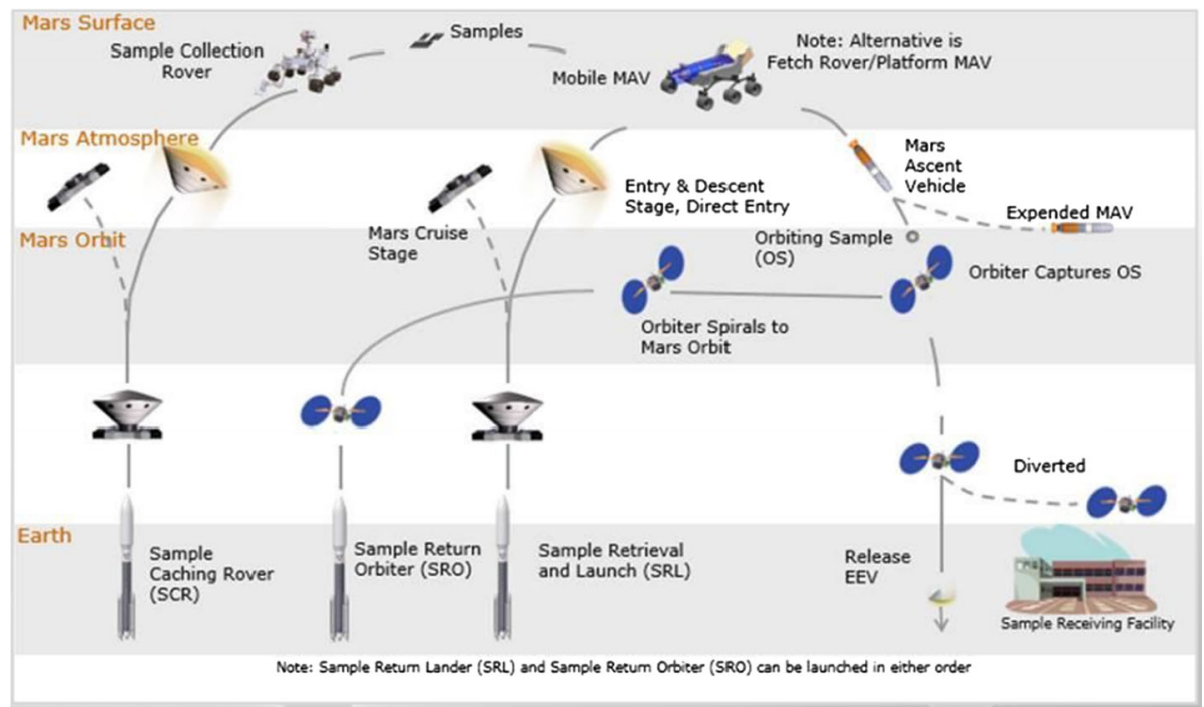

Fig. 2 Possible architecture for a Mars Sample Return Campaign (from Haltigin et al. 2018)

up to the point of collection would have been in chemical equilibrium or steady state with the surrounding strata. Following that, the material will be in orbit around Mars or Earth, or in interplanetary space, each time experiencing a different set of thermal (and gravitational) conditions. However, when the sample tubes are sealed, the material inside will represent the conditions at the time of their collection. The environment of collection will be known and recorded, so enabling back calculation of the initial conditions of the material. This is important if we wish to infer water activity, redox potential, etc.

There are specific mineral species that are sensitive to changing environmental conditions, including phyllosilicates (clay minerals) and hydrated salts. Experiments have shown that reactions between anhydrous minerals and water (especially as brine) occur very rapidly, on a timescale of days, even at low temperature (Phillips-Lander et al. 2019). Hence reactions between mineral assemblages in the MSR collection tubes with water of crystallisation or inter-layer water released from clay minerals could change the chemical balance of the system and not be a true reflection of the hydration state of the original material collected. There could even be movement of cations during the reactions - for example, removal of aluminium from plagioclase would alter fluid composition and change the products of serpentinization of olivine (Pens et al. 2016). The conversion of Fe- and Mg-bearing phyllosilicates to Al-bearing silicates is a key marker for changing environmental conditions on Mars (Bishop et al. 2018). It is essential, if we are to be certain that the samples returned to Earth can be interpreted as representative of the material that was collected on Mars, that analyses are performed of the material whilst it is in situ on Mars.

\section{MSR Mission Design}

As currently planned, Mars Sample Return is not a mission, but a campaign of several missions; one possible architecture for the campaign, with the different component missions is shown in Fig. 2. 
(a)

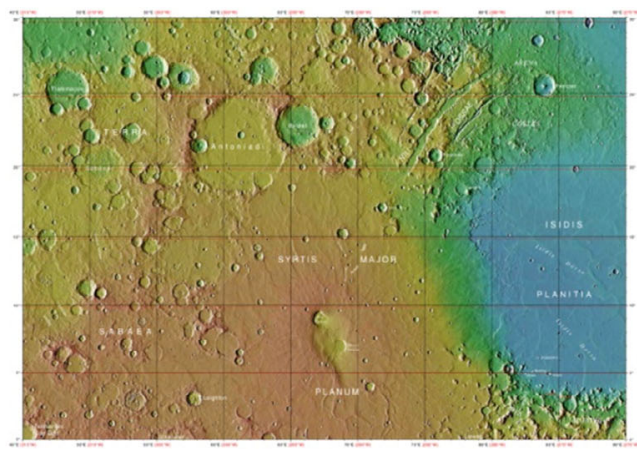

(b)

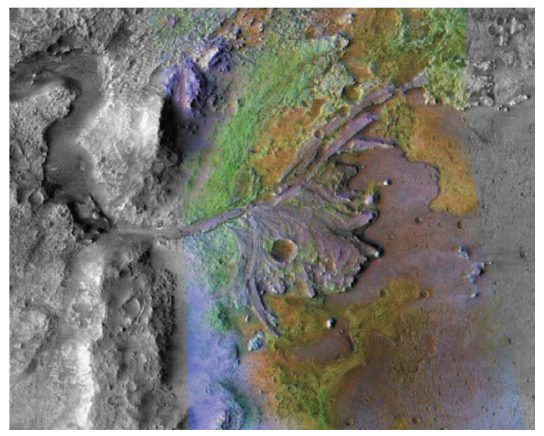

Fig. 3 The Mars2020 landing site, Jezero Crater. (a) Context map: Syrtis Major quadrangle MC13 centred on $15^{\circ} \mathrm{N} 292.5^{\circ} \mathrm{W}$; (b) Close-up of a delta on the NW edge of Jezero Crater. Image Credits: NASA/JPL-Caltech/MSSS/JHU-APL

In this scenario, the first mission is NASA's Mars-2020 rover, due to launch in July 2020. The rover has the same chassis as the highly-successful Curiosity rover, with a different complement of on-board instrumentation. An important part of the equipment is a drill which will produce small cores, about $5-6 \mathrm{~cm}$ long and $1 \mathrm{~cm}$ in diameter. The cores will be stored in sample tubes that will be cached on Mars' surface for retrieval by a subsequent mission. The Mars-2020 rover will land at Jezero Crater (Fig. 3); the prime mission aims to explore part of the delta that once debouched into the crater. The rover will collect and cache about 20 samples from different localities on the crater floor. If an extended campaign is approved, the rover would traverse the crater wall and navigate towards the Noachian deposits of NE Syrtis, caching a further set of samples $(\sim 20)$.

The return part of the MSR mission is co-funded by ESA and NASA. It comprises four separate elements carried on two spacecraft, both of which are currently scheduled for launch in 2026. The first launch, the NASA-led Sample Retrieval Lander, will carry three of the elements: NASA's Mars Ascent Vehicle (MAV), ESA's Fetch Rover and the Orbiting Sample canister (OS). The rover will collect the samples cached by Mars-2020 and return them to the MAV where they will be loaded into the OS canister; either the rover or the OS could carry tubes designed to collect atmospheric samples. The MAV will carry the OS canister for release into low Mars orbit.

The second launch, the ESA-led Earth Return Orbiter acts as a communications relay for the lander. Once the OS is launched into Mars orbit, the orbiter will pick it up, encapsulating it in the Earth Entry Vehicle and return it to Earth orbit. The planning schedule has landing of the Earth Entry Vehicle in 2032. The mission needs this level of complexity with different vehicles launching from Mars and returning to Earth in order to 'break the chain' of contact between the two planets. This is to conform with planetary protection requirements designed to ensure no contamination of the Earth by material returned directly from Mars (Rummel et al. 2002).

\section{Jezero Crater}

Jezero Crater $\left(77.5^{\circ} \mathrm{E} 18.4^{\circ} \mathrm{N}\right)$ was selected as the landing site for Mars 2020 in October 2018. It is a $45 \mathrm{~km}$ diameter crater on the west margin of Isidis Basin and just north of 
NE Syrtis (Fig. 3a). In the Late Noachian-Early Hesperian, there is thought to have been an open-basin paleolake up to $250 \mathrm{~m}$ deep within the crater (Goudge et al. 2012) into which a river debouched leaving behind a series of deltaic sediments (Goudge et al. 2017, 2018). The remains of a fan-shaped delta can clearly be seen in Fig. 3b. The lake drained a vast watershed to the South and West of Jezero (Fassett and Head 2005); sediments transported into the lake should be a mix of the erosion products of the differing rock types of the source region. The Mars 2020 rover will land on the crater floor, probably on to the series of lacustrine deposits that include olivine- and magnesium carbonate-bearing rocks (Ehlmann et al. 2008). Above these pale-coloured sediments that cover the original basement floor is a series of deltaic deposits displaying a range of alteration species (Goudge et al. 2017). The whole is capped by a unit that may be a lava flow or volcanic sediments derived from a flow (Goudge et al. 2015; Ruff 2017).

In sum, Jezero Crater is a sequence of lacustrine and fluvio-deltaic deposits, sampling of which during the prime mission would respond to the iMOST objectives for exploration of a sedimentary system (Objective 1.1; Beaty et al. 2019). If the mission is extended, then the (current) plan is to traverse the crater rim to collect material from the rim and of the Noachian-age mega-breccia related to the volcanic units of NE Syrtis. It is hoped that samples returned from Jezero would include material from the basement unit of the crater floor (if there are any exposures) plus samples of lacustrine sediments and deltaic material.

\subsection{What Might Be Learnt from the Jezero Crater Samples?}

As stated above, samples returned from Jezero Crater will be appropriate to address Objective 1.1 of the iMOST objectives: Interpret the Primary Geologic Processes and History that Formed the Martian Geologic Record, with an Emphasis on the Role of Water (Beaty et al. 2019). In other words, returned samples will be used to understand the processes, timing, geochemistry, and biological potential of a sedimentary system. Lacustrine basins like that of Jezero Crater keep a good record of paleoenvironmental and paleoclimatic conditions because they often have a continuous stratigraphy (e.g., Smoot and Lowenstein 1991; Renaut and Last 1994), independent of whether or not the basin has been open (i.e., has outflowing rivers or streams or has over-flowed a crater margin) or closed. Knowing already that Jezero Crater contains rocks produced by fluvial, lacustrine and aeolian processes (Goudge et al. 2012, 2015, 2017, 2018), then acquisition of samples from the different strata will be essential to disentangle the history of the Jezero palaeolake and its surrounding catchment area. As well as the provenance of the material that formed the sediments, specific processes that operated on the sediments would be studied, including diagenesis, weathering, transport and deposition. Once the history of surface and near-surface water and its interactions with the sediments and the atmosphere is developed, a record of the ancient climate of Mars preserved in the resultant rocks should be revealed, constraining models for the range of past climate variations. The results will enable construction of an evolutionary timeline for the basin, providing absolute ages for sedimentary deposition under different environments (fluvial, lacustrine, aeolian). If the current understanding of the geology of Jezero Crater is correct, then samples obtained from the crater floor should be volcanic, further elucidating the history of the crater, presumably placing an upper limit on its formation age.

A significant parallel set of investigations to the chronological question is the search for preservation of organic material and assessment of the biological potential of the material. One of the reasons that Jezero crater was selected as the landing site for Mars 2020 is that palaeolakes are an ideal location for the deposition and preservation of organic material. Samples returned from the crater may contain evidence of martian life, even if at the biomarker level rather than as fossils (Summons et al. 2011). 
An additional benefit of studying a suite of samples from Jezero crater is that the results will allow reconstruction of an entire martian sedimentary system, from which it should be possible to apply the results to other sedimentary regions observed from orbit.

\subsection{Using Returned Samples for Evaluation of Potential Hazards to Human Exploration}

The return of samples to Earth from Mars is also an important part of any Human Exploration programme (NASA 2009). At the most basic of levels, the mission would demonstrate that a spacecraft could lift off from a body with significant gravity and an atmosphere and return to Earth safely. As well as this most fundamental aspect of the relevance of MSR, the iMOST report established three separate areas in which returned samples would contribute: planetary protection, engineered systems safety and hazards to human health. Planetary protection has been discussed earlier and there are no specific additional concerns for human space exploration. The safety, efficiency and effectiveness of engineered systems, such as breathing apparatus, transport, power generation, etc., are likely to be reduced following exposure to martian dust. There are many examples from the Apollo missions (e.g., Gaier 2005; Kobrick and Agui 2019) where dust abraded space suits, infiltrating joints and seals, and the likelihood of a similar effect on Mars is high. The presence of a martian atmosphere means that wind can lift and transport dust, turning the dust into a very efficient agent of abrasion; the long duration of a martian mission would cause exposed surfaces to be scoured and seals to degrade.

Whilst there is a need to test the resistance of spacesuits and other systems to the effects of martian dust, it is unlikely that samples returned from Mars would be available for such experiments, even if they were suitable. The MSR mission currently being planned will return limited amounts of sample, mainly rocks. It is not scheduled to collect airfall dust, which is the material required in relatively large quantities for testing. However, the returned tubes, which will have been exposed on the martian surface for around 10 years, will almost certainly be covered in dust - and it is possible that this material might be suitable for the abrasion testing. What is likely to be more useful, though, is that collection and characterisation of the airfall dust from the exterior surfaces of the sample tubes will help in production of a high-quality dust simulant. The grain size, shape, angularity, composition and density of the airfall dust will be replicated and large quantities synthesised, enabling large-scale testing of engineering systems to be undertaken.

Infiltration of dust through joints and seals is a hazard to astronaut health as well as to engineering systems. Analysis of the returned samples, especially the airfall dust, would take place as part of the planetary protection procedures to determine whether there were any biological or geochemical hazards in the samples that might affect humans. "Breaking the chain of contact" when leaving Mars is currently a requirement for containment of all material returning from Mars including any mission items that have been exposed to the martian environment. Whilst this can be put into practice for autonomous missions, it is certainly not practicable for missions involving astronauts - no matter how well-designed future generations of space hardware (including spacesuits) are, it is highly likely that astronauts will come into contact with martian dust, as was the case for Apollo astronauts and lunar dust (NRC 2002; Gaier 2005; NASA 2009; COSPAR 2011). One of the most important goals of sample return will be to determine the toxicity of martian material, and whether or not it comprises a biological hazard. 
Table 1 Science Objectives for Mars Sample Return (Beaty et al. 2019)

Shorthand Full Statement

Objective 1: Geological environment $(s)$

Interpret the primary geologic processes and history that formed the martian geologic record, with an emphasis on the role of water

1.1 Sedimentary System

Characterize the essential stratigraphic, sedimentologic, and facies variation of a sequence of martian sedimentary rocks

$1.2 \quad$ Hydrothermal

Understand an ancient martian hydrothermal system through study of its mineralization products and morphological expression

Deep subsurface groundwater

Understand the rocks and minerals representative of a deep subsurface groundwater environment

Subaerial

Igneous terrane

Understand water/rock/atmosphere interactions at the martian surface and how they have changed with time

Objective 2: Life

Determine the petrogenesis of martian igneous rocks in time and space

Assess and interpret the potential biological history of Mars, including assaying returned samples for the evidence of life

Carbon chemistry

Biosignatures-ancient

\section{Biosignatures-modern}

Objective 3: Geochronology

Objective 4: Volatiles

Objective 5: $\quad$ Planetary-scale geology

Assess and characterize carbon, including possible organic and pre-biotic chemistry

Assay for the presence of biosignatures of past life at sites that hosted habitable environments and could have preserved any biosignatures

Assess the possibility that any life forms detected are still alive, or were recently alive

Determine the evolutionary timeline of Mars

Constrain the inventory of martian volatiles as a function of geologic time and determine the ways in which these volatiles have interacted with Mars as a geologic system

Reconstruct the history of Mars as a planet, elucidating those processes that have affected the origin and modification of the crust, mantle and core

Objective 6: Environmental hazards

Understand and quantify the potential martian environmental hazards to future human exploration and the terrestrial biosphere

Objective 7: ISRU

Evaluate the type and distribution of in situ resources to support potential future Mars Exploration

\section{Science Goals}

There are many questions that remain unresolved about Mars. The iMOST report (Beaty et al. 2019) organised the questions into seven objectives (Table 1). Five of the objectives related to understanding the geological evolution of Mars, possible interactions between the geosphere and potential biosphere and signatures of life. The remaining two objectives were in support of human space exploration.

The first objective was specified to 'Interpret the primary geologic processes and history that formed the martian geologic record, with an emphasis on the role of water'. It had 


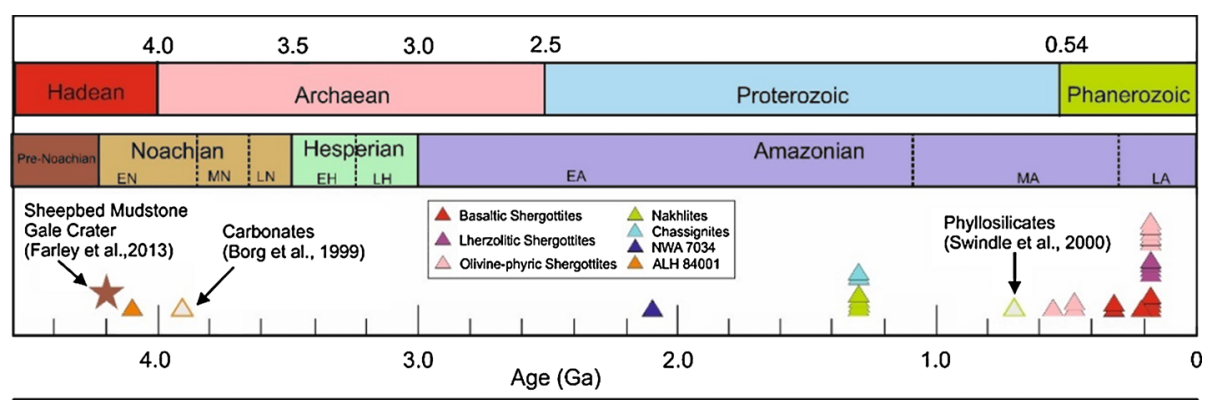

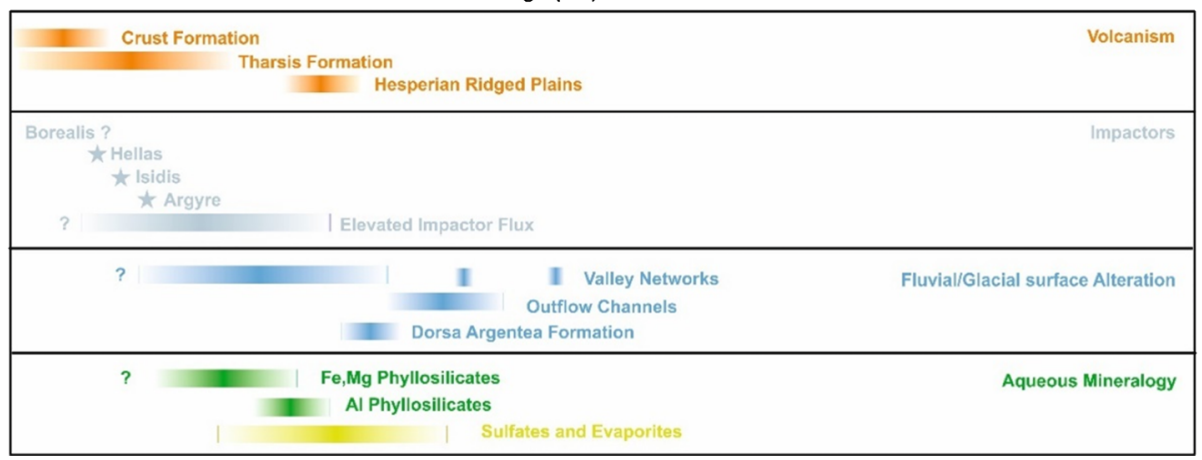

Fig. 4 Timeline of major events in Mars' history, with the geologic aeons of Earth. Question marks indicate cases where processes could also have occurred earlier but the geologic record is obscured by subsequent events. Figure and caption adapted from Wordsworth (2016). Based on data from Ehlmann et al. (2011), Fassett and Head (2011), Head and Pratt (2001), Werner (2019) and Werner and Tanaka (2011). Martian meteorite data from Borg et al. (1999), Swindle et al. (2000), Nyquist et al. (2001), Agee et al. (2013). Gale Crater data from Farley et al. (2013)

five sub-objectives, related to different geological environments (sedimentary, hydrothermal, deep sub-surface groundwater, sub-aerial and igneous). Since selection of Jezero Crater as the landing site for the Mars 2020 rover, the first sub-objective now relates directly to a sedimentary environment. We highlight here two headline issues that demonstrate the importance of sample return in order to address the science goals.

\subsection{An Absolute Age for the Martian Surface}

One of the most significant pieces of information missing from our understanding of Mars is its age. We know that it aggregated from the same presolar cloud as the rest of the Solar System, so its fundamental age is about $4567 \mathrm{Ma}$. We also know that there has been significant differentiation of the planet and that it has a crust, mantle and core. The core is almost certainly solid, as is the mantle. Surface morphology and specific features (impact craters, volcanoes and river and valley networks) give relative chronologies (Fig. 4); combined with almost global coverage of high-resolution imagery, a detailed timeline for the physical evolution of Mars can be constructed (Tanaka et al. 2014). Although the extent of spectroscopic data (for chemical and mineralogical compositions) is less complete than that of imagery, it has also been possible to construct a timeline for the chemical evolution of the planet that can be matched with the physical timeline. There are, however, no absolute ages of either bedrock or regolith that can definitively tie down the chronology (e.g., Bibring et al. 2006; Murchie et al. 2009; Ehlmann et al. 2016). We can place some specific anchor points on 
the timeline from the absolute ages of martian meteorites. The different compositional types have distinct ages which can be linked with the cratering and compositional chronologies but cannot definitively assign dates to specific events or epochs because we lack knowledge of the specific sites on Mars from which the martian meteorites were ejected. So we have a situation with two end-members: martian meteorites give us an absolute age, but no geographical context. Remote sensing data acquired by orbiting spacecraft have yielded relative ages for physical and chemical events but have no way of anchoring the events to absolute ages.

Instruments on-board the Curiosity rover measured the K-Ar of the Sheepbed Mudstones within Gale Crater as $4.21 \pm 0.35 \mathrm{Ga}$ (Farley et al. 2014). A second determination, of the Windjana sandstone failed (Vasconcelos et al. 2016). A third age measurement, of the Mojave 2 mudstone was undertaken in two temperature increments, to distinguish secondary alteration products from primary material (Martin et al. 2017). The results showed that detrital plagioclase (presumably from older igneous rocks) had an age of $4.07 \pm 0.63 \mathrm{Ga}$ whilst jarosite produced by subsequent weathering had an age of $2.12 \pm 0.36 \mathrm{Ga}$. These ages are a start in construction of a timeline for the sedimentary history of Gale Crater and the chronology of martian secondary processes but are not able to address issues of the nature and inferred history (primary differentiation and crystallisation) of the mantle source of the magmas from which the sedimentary rocks were derived.

The samples collected at Jezero Crater will mainly be sedimentary in nature and so, by definition, are not primary igneous materials that record a formation age. It is hoped that at least some of the crater floor will be exposed for collection of (potentially) late Noachian volcanic flows. Nonetheless, some of the most ancient ages for terrestrial rocks have come from analyses of detrital minerals in sedimentary-derived materials (Cavosie et al. 2004). $\mathrm{U}-\mathrm{Pb}$ ages of individual grains of zircon and monazite from terrestrial impact craters have retained their original formation age despite having experienced subsequent hydrothermal processing (Moser 1997). The sediments from Jezero crater may provide analogous materials, as the sediments that fill the crater have been drawn from a catchment area that encompasses primary igneous rocks. Sample return is definitely essential for age-dating studies of this nature, because of the necessity to separate individual grains that have not been altered by subsequent processing.

\subsection{Organics and Life?}

The driving force for almost all martian exploration has been the prospect of finding life on the planet - if not extant life, then signs that life had been present at times in Mars' past. The first attempt to find life on Mars came with the Viking mission of 1977 (Klein 1978). The two landers each carried an experiment package to test the martian soil for evidence of metabolic activity. The results were almost uniformly negative - and the sole positive result was entirely explicable in terms of a chemical, not biological, reaction (Navarro-González et al. 2010). Since the Viking experiments, we have learnt an enormous amount about the martian surface, especially about the range of highly-oxidising salts (especially perchlorates) present in the soil (Lasne et al. 2016). The salts, together with the ever-present solar $\mathrm{UV}$ radiation, combine to ensure that the martian surface is probably free of the types of organic molecules that might be diagnostic of living cells. However, there may well be a more benign environment for survival of organic material below the surface. In July 2022, ESA's ExoMars 2022 mission will be launched; one of its main goals is to search for evidence of organic compounds. To do this, it will deploy a $2 \mathrm{~m}$-length drill to penetrate below Mars' surface in order to search for organic (and biological) material below any likely oxidised 
horizons. This will be the first time that rocks that have not been exposed to surface radiation will be analysed - and it is hoped that the presence of biologically significant molecules will be detected.

One tenet that underlies the search for life on Mars is that it is likely to be carbon-based. There are good physical and chemical explanations for why this is an acceptable assumption, especially given that Mars and Earth were formed from the same starting materials at the same time and for the earliest part of their histories experienced the same processes (impact bombardment, differentiation, etc.). The presence of reduced carbon is taken to be a significant marker for the potential discovery of evidence of life or prebiotic chemistry in a sample (Sephton and Botta 2005). The sediments of Gale Crater have been shown to be relatively rich in organic carbon (Freissinet et al. 2015; Sutter et al. 2017), but as yet have not yielded any evidence for definitive biological signatures.

It is hoped that the samples returned by the current MSR campaign will be collected from below horizons affected by solar irradiation. The second objective of the iMOST report (Beaty et al. 2019) concerned the range of investigations that should be undertaken to investigate the likelihood of life being present in the returned material. The objective was sub-divided into three: firstly, to investigate carbon - its occurrence, sources and characteristics - to determine its biotic or abiotic nature. The second part is designed to look for signs of ancient (fossilised) life by comparing the structure of any carbon-bearing entities found in the martian samples with ancient terrestrial biosignatures. Finally, there would be a search for signs of current life, again using the presence of biosignatures as a diagnostic tool.

Although organics have been measured in situ by the Curiosity rover, the series of chemical derivatisations intended to characterise specific organic compounds in the sediments have not yet been successfully completed. The reaction steps required to determine the organic inventory of a sample, and the associated range of chemicals and temperature regimes required, make for an extremely precise and complex undertaking. Such a sequence of steps is only possible on returned samples - and as outlined in Sect. 5, almost all the samples that will be collected from Jezero Crater have the potential to address the question of life on Mars.

\section{Planetary Protection (PP)}

The United Nations, through COSPAR (Committee on Space Research), has responsibility for Planetary Protection (PP), both the prevention of contamination of the Earth from potentially harmful agents (backward PP) and prevention of contamination of bodies beyond Earth by terrestrial agents (forward PP). For a sample return mission, both aspects of PP must be considered: forward PP on the collected samples and backward PP during transport, curation and analysis.

There are five planetary protection categories defined by COSPAR; all Earth return missions are Category V and a Mars Sample Return mission is Category Vb (Restricted Earth Return), the requirements for which are given as follows:

The absolute prohibition of destructive impact upon return, the need for containment throughout the return phase of all returned hardware which directly contacted the target body or unsterilized material from the body, and the need for containment of any unsterilized sample collected and returned to Earth. Post-mission, there is a need to conduct timely analyses of any unsterilized sample collected and returned to Earth, under strict containment, and using the most sensitive techniques. If any sign of the 
existence of a non-terrestrial replicating entity is found, the returned sample must remain contained unless treated by an effective sterilizing procedure (COSPAR 2011; Kminek et al. 2017).

Design studies for an MSR Receiving and Curation Facility have examined facilities in which biohazardous material is stored on Earth. The most recent reports are Euro-CARES (2017) and MSPG (2019a, 2019b). The most strictly-controlled of such facilities is BSL-4, where all possible precautions are taken to prevent material escaping (backward PP). Less attention is given to material coming into the laboratory (forward PP). Currently, there is no existing facility that maintains high level containment in both the backwards and forwards direction, hence the need for a specially-designed facility for returned martian samples.

It has sometimes been the case in previous design studies that the requirements for PP have been seen to be in conflict with those of the science goals. It is now recognised that many of the analyses designed to respond to PP questions about the potentially hazardous nature of martian materials are the same as those that would be applied to answering science questions about the presence (or absence) of biological matter and its characteristics. The benefit of the change in approach to both PP and Science goals is that there is likely to be a more efficient and stream-lined analytical sequence for the preliminary investigations, possibly with a more rapid outcome to decision-making about release of samples from containment (MSPG 2019a, 2019b).

\section{Sample Receiving and Curation Facility(ies)}

A hugely important part of an MSR campaign is the facility (or facilities) that will support the processing, basic characterization, and eventual allocation of the material on its return to Earth. At present, although final decisions about the return part of the mission have not yet been taken, it is almost certain that the designated landing site of the cannister containing the samples will be in the U.S. This will require a sample retrieval facility to be based in the landing area, as was the case for the Genesis and Stardust missions (McCubbin et al. 2019). Processing and opening of the cannister and all subsequent activities are governed by planetary protection concerns; the chain of what happens and when and where it happens is under current consideration.

Once the samples are returned from Mars, there will be a systematic process to evaluate the type of material that has been recovered. In order to ensure fair access to samples by the community and also to carry out and evaluate the required series of tests for planetary protection purposes, it is likely that there will be an international board established to oversee a preliminary examination of returned Martian samples as well as its subsequent distribution. The structure and governance of the body that will oversee the MSR sample curation, analysis and distribution is under consideration (MSPG 2019c).

The samples will be moved from the landing site to a Sample Receiving Facility (SRF). This will be combined with (indeed, act as) a Sample Curation Facility (SCF). There will only be a single SRF - and if, as is assumed, the sample cannister lands in the U.S., the SRF will be in the U.S. However, there almost certainly will be more than one SCF: one will be part of the SRF and at least one will be in Europe (MSPG 2019a, 2019b). For simplicity, in the rest of this section, we refer simply to a Sample Curation Facility (SCF).

\subsection{Preliminary Analyses}

Staff at the SCF would be responsible for sample curation and eventual allocation of samples to the international community; allocation would (presumably) be decided by an interna- 
tional allocation committee operating under the auspices of an oversight board. There have been many studies outlining how such a facility might operate, what instruments should be installed and the analyses that should be performed. Planetary protection protocols for different areas and processes within the SCF are under active discussion, under the auspices of COSPAR. There are many issues that have to be considered prior to analysis of a sample. The most recent study that has deliberated on potential operations models for an SRF is the MSPG joint ESA-NASA Working Group (MSPG 2019a, 2019b). In its reports, the MSPG recognised two phases of examination that the samples would undergo in the first instance: Basic Characterisation (BC) and Preliminary Examination (PE). Both phases would take place under full BSL-4 conditions.

An outline of a possible sequence of events is as follows. BC is non-invasive and nondestructive - it comprises, as a minimum, photography and weighing of the sample tubes. All sample tubes would go through BC on arrival at the SCF. The next phase of investigation, $\mathrm{PE}$, is more detailed, minimally invasive and non-destructive. It is likely to be carried out on a single tube at a time.

There are still huge unresolved issues of how BC and PE would take place: one particular concern is the dust that will cover the tubes - it is likely to permeate the cannister and will have to be collected at different stages of the cannister and sample tube opening procedures. Other issues include: (i) how the headspace gases above the tubes should be extracted and what, if anything, the tubes should be re-pressurised with; (ii) the desirability (or otherwise) of CT scanning of the tubes prior to removal of the sample; (iii) if, when and how material should be sterilised prior to distribution and (iv) how much sample will be assigned for PP testing and how will it be selected, etc. It is clear that whatever instruments and techniques are selected to perform the BC and PE analyses, they must generate sufficient relevant information to characterise the samples, enabling decision-making during the subsequent allocation process. Most of these considerations are detailed in MSPG 2019a, 2019b, and so will not be covered here.

\subsection{Instrumentation}

The international community has made several different attempts to determine the type of instrumentation and analysis that will be required for complete characterisation of the return samples. The required analyses can be divided up into the following categories: (i) morphology, structure and texture; (ii) mineralogy and mineral chemistry; (iii) organic components and (iv) isotopic composition. As yet undetermined is the split between which instruments and analyses would be carried out within the SCF as part of BC and PE, which analyses have to be undertaken quickly because of time-dependent considerations (e.g., disequilibrium reactions involving water activity once a tube is opened) and which analyses might be carried out on sterilised samples. MSPG (2019a) summarizes recent community consideration of this topic.

The following table is a compilation of the instruments regarded by the Euro-CARES consortium as being appropriate for installation within the SCF. The Table is divided on the basis of the examination stage that a sample is undergoing. It is probably redundant to repeat that no decisions have yet been reached as to which equipment or instruments would be required. It is also almost certain that samples would be processed within the SCF for allocation outside the SCF to individual investigators or groups with specialist instruments that will acquire data beyond that acquired within the SRF by the instruments listed in Table 2. Again, the issue of analytical instrumentation is discussed further in the iMOST and MPSG reports (Beaty et al. 2019; MSPG 2019a, 2019b, 2019c). 
Table 2 Range of instruments and equipment identified as required in a Sample Curation Facility (EUROCARES, 2018)

\begin{tabular}{|c|c|}
\hline Sample Preparation Equipment & Comment \\
\hline Sputter coaters & For SEM analyses \\
\hline Microtome & For small samples \\
\hline Ion Micromills & For small samples \\
\hline Micromanipulators & Electrostatic tips, micro-tweezers for different sizes \\
\hline Integrated preparation systems & High precision cut, grind and polish system \\
\hline High precision saws & Diamond wheel (band saw for large samples) \\
\hline Grind and polish systems & Automated high precision for polished sections \\
\hline Instruments for Basic Characterisation & Comment \\
\hline Low magnification microscopes & Multiple microscopes required \\
\hline High magnification microscopes & Petrographic and Materials microscopes \\
\hline 3D imaging/shape profiler & Requires technology development \\
\hline High precision balances & Several required for a wide mass range \\
\hline Scanning Near Field Optical Microscope (SNOM) & Only for some samples ( $<$ few micron particle size $)$ \\
\hline Instruments for Preliminary Examination & Comment \\
\hline FTIR Microscope & Spectral imaging detectors for rapid high resolution \\
\hline Laser Raman Microscope & UV resonance Raman useful for organic analyses \\
\hline X-Ray CT (sample) & Separate X-Ray CT for sample tubes \\
\hline Micro-XRD & May be superseded by spectral X-Ray CT advances \\
\hline Analytical SEM & Multi-detector environmental SEM for insulators \\
\hline Focussed Ion Beam-SEM & Micron-scale selection of areas for TEM study \\
\hline Analytical TEM & Nanometre- to micrometre-scale analyses \\
\hline Optical Microscopy & High resolution \\
\hline
\end{tabular}

\section{Summary}

Decades of observation of Mars by fly-by, orbiting, landed and roving spacecraft, complemented by data from ground- and space-based telescopes and martian meteorites, have resulted in an enormous dataset of information. This has enabled a detailed picture of the planet to be built up. We have been able to infer relative chronologies for Mars' formation and its atmospheric, fluvial and volcanic histories. We have evaluated the likelihood (or otherwise) of the evolution and survivability of life and the suitability of Mars as a target for human exploration. But despite these advances, we do not know the age of Mars' crust or mantle, or when water flowed across the surface, or when spectacular volcanic eruptions took place. We can only obtain such information by returning samples from Mars to laboratories on Earth. Only then will detailed studies, carried out on carefully-prepared, highly-specific components of the martian samples complemented by high resolution, high magnification imagery, deliver the absolute chronology of Mars.

The return of samples from Mars is an essential next step in understanding the origin and evolution of our neighbouring planet. It is also a critical requirement for the safe return of future martian astronauts. 
Table 2 (Continued)

Instruments for Planetary Protection Analyses

Type of Biosignature

Optical Microscopy

Morphological

Electron Microscopy SEM

Morphological

Gas Chromatography-Mass Spectrometry (GC-MS)

Chemical

Liquid Chromatography-Mass Spectrometry (LC-MS)

Chemical

Matrix-Assisted Laser Desorption/Ionisation (MALDI)

Chemical

Time of Flight (TOF) mass spectrometry

Fluorescence microscope

Chemical

Raman spectrometer

Chemical

High Performance Liquid Chromatography (HPLC)

Chemical

Polymerase Chain Reaction (PCR) system

Biochemical

Enzyme-linked immune-absorbent assay system (ELISA)

Biochemical

Fluorescent In Situ Hybridisation (FISH) system

Biochemical

Sequencing

Biochemical

Chromatography

Biochemical

Protein micro-array (marker chip)

Biochemical

Secondary Ion Mass Spectrometry (SIMS)

Isotopic

Isotope Ratio Mass Spectrometry (IRMS)

Isotopic

${ }^{13}$ C-Nuclear Magnetic Resonance spectroscopy (NMR)

Isotopic

SEM-EDX

Mineralogical

$\mathrm{X}$-Ray Fluorescence (XRF)

Mineralogical

X-Ray CT

Mineralogical

X-Ray Diffraction (XRD)

Mineralogical

Note: Many of the instruments are duplicated because they are used for several purposes. The list does not imply (unless specifically recognised) that physical duplicates of the instruments are required

Acknowledgements The author has drawn heavily on the iMOST report to produce this paper, and would like to acknowledge the iMOST team, particularly Dave Beaty and Brandi Carrier, for the work that went into producing the document. Gratitude is expressed to Michael Velbel for a thorough and helpful review. Funding from the European Space Agency and the UK Space Agency is gratefully acknowledged.

Publisher's Note Springer Nature remains neutral with regard to jurisdictional claims in published maps and institutional affiliations.

Open Access This article is licensed under a Creative Commons Attribution 4.0 International License, which permits use, sharing, adaptation, distribution and reproduction in any medium or format, as long as you give appropriate credit to the original author(s) and the source, provide a link to the Creative Commons licence, and indicate if changes were made. The images or other third party material in this article are included in the article's Creative Commons licence, unless indicated otherwise in a credit line to the material. If material is not included in the article's Creative Commons licence and your intended use is not permitted by statutory regulation or exceeds the permitted use, you will need to obtain permission directly from the copyright holder. To view a copy of this licence, visit http://creativecommons.org/licenses/by/4.0/.

\section{References}

C.B. Agee, N.V. Wilson, F.M. McCubbin, K. Ziegler, V.J. Polyak, Z.D. Sharp, Y. Asmerom, M.H. Nunn, R. Shaheen, M.H. Thiemens, A. Steele, M.L. Fogel, R. Bowden, M. Glamoclija, Z. Zhang, S.M. Elardo, 
Unique meteorite from early Amazonian Mars: water-rich basaltic breccia Northwest Africa 7034. Science 339, 780-785 (2013). https://doi.org/10.1126/science.1228858

D.W. Beaty, M.M. Grady, H.Y. McSween, E. Sefton-Nash, B.L. Carrier (the iMOST Team), Meteorit. Planet. Sci. 54, S3-S152 (2019). https://doi.org/10.1111/maps.13242

R.H. Becker, R.O. Pepin, The case for a Martian origin of the Shergottites: Nitrogen and Noble gases in EETA79001. Earth Planet. Sci. Lett. 69, 225-242 (1984)

C.C. Bedford, J.C. Bridges, S.P. Schwenzer, R.C. Wiens, E.B. Rampe, J. Frydenvang, P.J. Gasda, Alteration trends and geochemical source region characteristics preserved in the fluviolacustrine sedimentary record of Gale crater, Mars. Geochim. Cosmochim. Acta 246, 234-266 (2019). https://doi.org/10.1016/ j.gca.2018.11.031

J.-P. Bibring et al., Global mineralogical and aqueous Mars history derived from OMEGA/Mars express data. Science 312, 400-404 (2006). https://doi.org/10.1126/science.1122659

J.L. Bishop, E.Z.N. Dobrea, N.K. McKeown, M. Parente, B.L. Ehlmann, J.R. Michalski, R.E. Milliken, F. Poulet, G.A. Swayze, J.F. Mustard, S.L. Murchie, J.-P. Bibring, Phyllosilicate diversity and past aqueous activity revealed at Mawrth Vallis, Mars. Science 321, 830-833 (2008). https://doi.org/10.1126/science. 1159699

J.L. Bishop, A.G. Fairén, J.R. Michalski, L. Gago-Duport, L.L. Baker, M.A. Velbel, C. Gross, E.B. Rampe, Surface clay formation during short-term warmer and wetter conditions on a largely cold ancient Mars. Nat. Astron. 2, 206-213 (2018). https://doi.org/10.1038/s41550-017-0377-9

D.D. Bogard, P. Johnson, Martian gases in an Antarctic meteorite? Science 221, 651-654 (1983)

L.E. Borg, J.N. Connelly, L.E. Nyquist, C-Y. Shih, H. Wiesmann, Y. Reese, The age of the carbonates in the Martian meteorite ALH84001. Science 286, 90-94 (1999)

J.C. Bridges, D.C. Catling, J.M. Saxton, T.D. Swindle, I.C. Lyon, M.M. Grady, Alteration assemblages in Martian meteorites: implications for near-surface processes. Space Sci. Rev. 96, 365-392 (2001)

J.C. Bridges, S.P. Schwenzer, R. Leveille, F. Westall, R.C. Wiens, N. Mangold, T. Bristow, P. Edwards, G. Berger, Diagenesis and clay mineral formation at Gale Crater, Mars. J. Geophys. Res., Planets 120, 1-19 (2015)

J. Carter, F. Poulet, J.-P. Bibring, N. Mangold, S. Murchie, Hydrous minerals on Mars as seen by the CRISM and OMEGA imaging spectrometers: updated global view. J. Geophys. Res., Planets 118, 831-858 (2013)

A.J. Cavosie, S.A. Wilde, D. Liu, P.W. Weiblen, J.W. Valley, Internal zoning and U-Th-Pb chemistry of Jack Hills detrital zircons: a mineral record of early Archean to Mesoproterozoic (4348-1576Ma) magmatism. Precambrian Res. 135, 251-279 (2004). https://doi.org/10.1016/j.precamres.2004.09.001

R.N. Clayton, T.K. Mayeda, Oxygen isotopes in eucrites, shergottites, nakhlites and chassignites. Earth Planet. Sci. Lett. 62, 1-6 (1983)

COSPAR Planetary Protection Policy, (2011). COSPAR/IAU Workshop on Planetary Protection Retrieved from https://cosparhq.cnes.fr/sites/default/files/pppolicy.pdf

B.L. Ehlmann, C.S. Edwards, Mineralogy of the Martian surface. Annu. Rev. Earth Planet. Sci. 42, 291-315 (2014)

B.L. Ehlmann, J.F. Mustard, C.I. Fassett, S.C. Schon, J.W. Head III., D.J. Des Marais, J.A. Grant, S.L. Murchie, Clay minerals in delta deposits and organic preservation potential on Mars. Nat. Geosci. 1, 355-358 (2008). https://doi.org/10.1038/ngeo207

B.L. Ehlmann, J.F. Mustard, R.N. Clark, G.A. Swayze, S.L. Murchie, Evidence for low-grade metamorphism, hydrothermal alteration, and diagenesis on Mars from phyllosilicate mineral assemblages. Clays Clay Miner. 59, 359-377 (2011)

B.L. Ehlmann, G.A. Swayze, R.E. Milliken, J.F. Mustard, R.N. Clark, S.L. Murchie, G.N. Breit, J.J. Wray, B. Gondet, F. Poulet, J. Carter, W.M. Calvin, W.M. Benzel, K.D. Seelos, Discovery of alunite in Cross crater, Terra Sirenum, Mars: evidence for acidic, sulfurous waters. Am. Mineral. 101, 1527-1542 (2016). https://doi.org/10.2138/am-2016-5574

Euro-CARES, European curation of astromaterials returned from exploration of space. D7.2 Final Technical Report (2017). http://www.euro-cares.eu/reports

K.A. Farley, J.A. Hurowitz, P.D. Asimow, N.S. Jacobson, J.A. Cartwright, A double-spike method for KAr measurement: A technique for high precision in situ dating on Mars and other planetary surfaces. Geochim. Cosmochim. Acta 110, 1-12 (2013). https://doi.org/10.1016/j.gca.2013.02.010

K.A. Farley, C. Malespin, P. Mahaffy, J.P. Grotzinger, P.M. Vasconcelos, R.E. Milliken, M. Malin, K.S. Edgett, A.A. Pavlov, J.A. Hurowitz, J.A. Grant, H.B. Miller, R. Arvidson, L. Beegle, F. Calef, P.G. Conrad, W.E. Dietrich, J. Eigenbrode, R. Gellert, S. Gupta, V. Hamilton, D.M. Hassler, K.W. Lewis, S.M. McLennan, D. Ming, R. Navarro-González, S.P. Schwenzer, A. Steele, E.M. Stolper, D.Y. Sumner, D. Vaniman, A. Vasavada, K. Williford, R.F. Wimmer-Schweingruber (the MSL Science Team), In situ radiometric and exposure age dating of the martian surface. Science 343 (2014). https://doi.org/10.1126/ science. 1247166 
C.I. Fassett, J.W. Head, Fluvial sedimentary deposits on Mars: ancient deltas in a crater lake in the Nili Fossae region. Geophys. Res. Lett. 32, L14201 (2005). https://doi.org/10.1029/2005GL023456

C.I. Fassett, J.W. Head, Sequence and timing of conditions on early Mars. Icarus 211, 1204-1214 (2011). https://doi.org/10.1016/j.icarus.2010.11.014

I.A. Franchi, I.P. Wright, A.S. Sexton, C.T. Pillinger, The oxygen-isotopic composition of Earth and Mars. Meteorit. Planet. Sci. 34, 657-661 (1999)

C. Freissinet et al., Organic molecules in the Sheepbed Mudstone, Gale Crater, Mars. J. Geophys. Res., Planets 120, 495-514 (2015)

J. Gaier, The effects of lunar dust on EVA systems during the Apollo missions. NASA/TM-213610 (2005). https://ntrs.nasa.gov/archive/nasa/casi.ntrs.nasa.gov/20050160460.pdf

T.A. Goudge, J.W. Head, J.F. Mustard, C.I. Fassett, An analysis of open-basin lake deposits on Mars: evidence for the nature of associated lacustrine deposits and post-lacustrine modification processes. Icarus $\mathbf{2 1 9}$, 211-229 (2012). https://doi.org/10.1016/J.ICARUS.2012.02.027

T.A. Goudge, J.F. Mustard, J.W. Head, C.I. Fassett, S.M. Wiseman, Assessing the mineralogy of the watershed and fan deposits of the Jezero crater paleolake system, Mars. J. Geophys. Res., Planets 120, 775-808 (2015). https://doi.org/10.1002/2014JE004782

T.A. Goudge, R.E. Milliken, J.W. Head, J.F. Mustard, C.I. Fassett, Sedimentological evidence for a deltaic origin of the western fan deposit in Jezero crater, Mars and implications for future exploration. Earth Planet. Sci. Lett. 458, 357-365 (2017). https://doi.org/10.1016/J.EPSL.2016.10.056

T.A. Goudge, D. Mohrig, B.T. Cardenas, C.M. Hughes, C.I. Fassett, Stratigraphy and paleohydrology of delta channel deposits, Jezero crater, Mars. Icarus 301, 58-75 (2018). https://doi.org/10.1016/J.ICARUS. 2017.09.034

L.L. Griffith, E.L. Shock, Hydrothermal hydration of Martian crust: illustration via geochemical model calculations. J. Geophys. Res. 102(E4), 9135-9143 (1997)

T. Haltigin, C. Lange, R. Mugnuolo, C. Smith (the iMARS Working Group), iMARS Phase 2: a draft mission architecture and science management plan for the return of samples from Mars. Astrobiology 18, 1-131 (2018)

J.W. Head, S. Pratt, Extensive Hesperian-aged south polar ice sheet on Mars: evidence for massive melting and retreat, lateral flow and ponding of meltwater. J. Geophys. Res. 106(E6), 12275-12300 (2001). https://doi.org/10.1029/2000JE001359

H.P. Klein, The Viking biological experiments on Mars. Icarus 34, 666-674 (1978). https://doi.org/10.1016/ 0019-1035(78)90053-2

G. Kminek, C. Conley, V. Hipkin, H. Yano, COSPAR's planetary protection policy. Space Res. Today 200, 12-25 (2017). https://doi.org/10.1016/J.SRT.2017.11.010

R.L. Kobrick, J. Agui, Preparing for planetary surface exploration by measuring habitat dust intrusion with filter tests during an analogue Mars mission. Acta Astron. 160, 297-307 (2019). https://doi.org/10.1016/ j.actaastro.2019.04.040

F.E. Kramer, D.B. Twedell, W.J.A. Walton Jr., Apollo-11 lunar sample information catalogue (revised) (1977). https://www.hq.nasa.gov/alsj/a11/A11SampleCat.pdf

J. Lasne, A. Noblet, C. Szopa, R. Navarro-González, M. Cabane, O. Poch, F. Stalport, P. François, S.K. Atreya, P. Coll, Oxidants at the surface of Mars: a review in light of recent exploration results. Astrobiology 16, 977-996 (2016). https://doi.org/10.1089/ast.2016.1502

M.R. Lee, L. Daly, B.E. Cohen, L.J. Hallis, S. Griffin, P. Trimby, A. Boyce, D.F. Mark, Aqueous alteration of the Martian meteorite Northwest Africa 817: Probing fluid-rock interaction at the nakhlite launch site. Meteorit. Planet. Sci. 53, 2395-2412 (2018). https://doi.org/10.1111/maps.13136

N. Mangold, M.E. Schmidt, M.R. Fisk, O. Forni, S.M. McLennan, D.W. Ming, V. Sautterg, D. Sumner, A.J. Williams, S.M. Clegg, A. Cousin, O. Gasnault, R. Gellert, J.P. Grotzinger, R.C. Wiens, Classification scheme for sedimentary and igneous rocks in Gale crater, Mars. Icarus 284, 1-17 (2017)

P.E. Martin, K.A. Farley, M.B. Baker, C.A. Malespin, S.P. Schwenzer, B.A. Cohen, P.R. Mahaffey, A.C. McAdam, D.W. Ming, P.M. Vasconcelos, R. Navarro-González, A two-step K-Ar experiment on Mars: dating the diagenetic formation of jarosite from Amazonian groundwaters. J. Geophys. Res., Planets 122, 2803-2818 (2017). https://doi.org/10.1002/2017JE005445

F.M. McCubbin, C.D.K. Herd, T. Yada et al., Advanced curation of astromaterials for planetary science. Space Sci. Rev. 215, 48 (2019). https://doi.org/10.1007/s11214-019-0615-9

D.S. McKay, E.K. Gibson, K.L. Thomas-Keprta, H. Vali, C.S. Romanek, S.J. Clemett, X.D.F. Chillier, C.R. Maechling, R.N. Zare, Search for life on Mars: possible relic biogenic activity in Martian meteorite ALH84001. Science 273, 924-930 (1996)

M. Melwani Daswani, S.P. Schwenzer, M.H. Reed, I.P. Wright, M.M. Grady, Alteration minerals, fluids, and gases on early Mars: predictions from 1-D flow geochemical modeling of mineral assemblages in meteorite ALH 84001. Meteorit. Planet. Sci. 51, 2154-2174 (2016) 
MSPG (MSR Science Planning Group: co-chairs M. Meyer, E. Sefton-Nash, f.D.W. Beaty, B.L. Carrier, D. Bass, F. Gaubert, T. Haltigin, A.D. Harrington, M.M. Grady, Y. Liu, D. Martin, B. Marty, R. Mattingly, S. Siljestrom, E. Stansbery, K. Tait, M. Wadhwa, L. White), C.C. Allen, H. Busemann, M. Calaway, M. Chaussidon, C.M. Corrigan, N. Dauphas, V. Debaille, D.P. Glavin, S.M. McLennan, K. Olsson-Francis, R. Shaheen, C.L. Smith, J. Thieme, T. Usui, M.A. Velbel, S.C. Werner, The relationship of MSR science and containment (2019a). Unpublished workshop report, posted 04/01/19 at https://mepag.jpl.nasa.gov/ reports/Science\%20in\%20Containment\%20Report\%20Final.pdf

MSPG (MSR Science Planning Group: co-chairs M. Meyer, E. Sefton-Nash, f.D.W. Beaty, B.L. Carrier, D. Bass, F. Gaubert, M.M. Grady, T. Haltigin, A.D. Harrington, Y. Liu, D. Martin, B. Marty, R. Mattingly, S. Siljeström, E. Stansbery, K. Tait, M. Wadhwa, L. White), A.M.B. Anesio, L. Bonal, A. Bouvier, J.C. Bridges, J.R. Brucato, K.L. French, U. Gommel, H.V. Graham, J.M.C. Holt, G. Kreck, R. Mackelprang, F.M. McCubbin, K. Olsson-Francis, A.B. Regberg, A. Saverino, M.A. Sephton, C.K. Sio, Sciencedriven contamination control issues associated with the receiving and initial processing of the MSR samples (2019b). Unpublished workshop report, posted 09/20/19 at https://mepag.jpl.nasa.gov/reports. cfm

MSPG (MSR Science Planning Group: co-chairs M. Meyer, E. Sefton-Nash, f.D.W. Beaty, B.L. Carrier, D. Bass, F. Gaubert, M.M. Grady, T. Haltigin, Y. Liu, D. Martin, B. Marty, R. Mattingly, S. Siljeström, E. Stansbery, K. Tait, M. Wadhwa, L. White), A framework for Mars returned sample science management (2019c). Unpublished white paper, posted 12/11/19 at https://mepag.jpl.nasa.gov/reports.cfm?expand= mspg

D.E. Moser, Dating the shock wave and thermal imprint of the giant Vredefort impact, South Africa. Geology 25, 7-10 (1997). https://doi.org/10.1130/0091-7613(1997)025<0007:DTSWAT>2.3.CO;2

S.L. Murchie, J.F. Mustard, B.L. Ehlmann et al., A synthesis of Martian aqueous mineralogy after 1 Mars year of observations from the Mars Reconnaissance Orbiter. J. Geophys. Res., Planets 114 (2009). https://doi.org/10.1029/2009JE003342

T.A. Mutch, S. Saunders, The geologic development of Mars: a review. Space Sci. Rev. 19, 3-57 (1976)

National Aeronautics and Space Administration, Human exploration of Mars: design reference architecture 5.0. NASA Pub. No. NASA-SP-2009-566 (2009). http://www.nasa.gov/pdf/373665main_NASA-SP2009-566.pdf

R. Navarro-González, E. Vargas, J. de la Rosa, A.C. Raga, C.P. McKay, Reanalysis of the Viking results suggests perchlorate and organics at midlatitudes on Mars. J. Geophys. Res. 115, E12010 (2010). https://doi.org/10.1029/2010JE003599

NRC (National Research Council), Safe on Mars: Precursor Measurements Necessary to Support Human Operations on the Martian Surface (National Academies Press, Washington, 2002). https://doi.org/10. $17226 / 10360$

L.E. Nyquist, D.D. Bogard, C-Y. Shih, A. Greshake, D. Stoffler, O. Eugster, Ages and geologic histories of Martian meteorites, in Chronology and Evolution of Mars (ISSI), vol. 96 (Kluwer Academic Publishers, The Netherlands, 2001), pp. 105-164

M. Pens, M. Andreani, I. Daniel, J.-P. Perillat, C. Herve, Contrasted effect of aluminum on the serpentinization rate of olivine and orthopyroxene under hydrothermal conditions. Chem. Geol. 441, 256-264 (2016)

R.O. Pepin, Evidence of Martian origins. Nature 317, 473-475 (1985)

C.M. Phillips-Lander, A.S. Elwood Madden, E.M. Hausrath, M.E. Elwood Madden, Aqueous alteration of pyroxene in sulfate, chloride and perchlorate brines: implications for post-Noachian aqueous alteration on Mars. Geochim. Cosmochim. Acta 257, 336-353 (2019)

E.B. Rampe, M.G.A. Lapotre, T.F. Bristow, R.E. Arvidson, R.V. Morris, C.N. Achilles, C. Weitz, D.F. Blake, D.W. Ming, S.M. Morrison, D.T. Vaniman, S.J. Chipera, R.T. Downs, J.P. Grotzinger, R.M. Hazen, T.S. Peretyazhko, B. Sutter, V. Tu, A.S. Yen, B. Horgan, N. Castle, P.I. Craig, D.J. Des Marais, J. Farmer, R. Gellert, A.C. McAdam, J.M. Morookian, P.C. Sarrazin, A.H. Treiman, Sand mineralogy within the Bagnold Dunes, Gale crater, as observed in situ and from orbit. Geophys. Res. Lett. 45, 9488-9497 (2018)

R.W. Renaut, W.M. Last (eds.), Sedimentology and Geochemistry of Modern and Ancient Saline Lakes (SEPM (Society for Sedimentary Geology) 1994). https://doi.org/10.2110/pec.94.50

K. Righter, Introduction to the Martian Meteorite Compendium (2017). https://curator.jsc.nasa.gov/antmet/ mmc/introduction2017update.cfm

S.W. Ruff, Investigating the floor of paleolake Jezero by way of Gusev crater, in 4th Int. Conf. on Early Mars: Geologic, Hydrologic, and Climatic Evolution and the Implications for Life. Abst. \#3076 (2017)

S.W. Ruff, J. Farmer, Silica deposits on Mars with features resembling hot spring biosignatures at El Tatio in Chile. Nat. Commun. 7, 13554 (2016). https://doi.org/10.1038/ncomms 13554

J.D. Rummel, M.S. Race, D.L. DeVincenzi, P.J. Schad, P.D. Stabekis, M. Viso, S.E. Acevedo, A draft test protocol for detecting possible biohazards in Martian samples returned to Earth, Washington, DC (2002). https://planetaryprotection.nasa.gov/summary/DraftTestProtocol 
M.A. Sephton, O. Botta, Recognizing life in the Solar System: guidance from meteoritic organic matter. Int. J. Astrobiol. 4, 269-276 (2005). https://doi.org/10.1017/S1473550405002806

J.P. Smoot, T.K. Lowenstein, Depositional environments of non-marine evaporites, in Developments in Sedimentology, vol. 50 (1991), pp. 189-347. Ch. 3. https://doi.org/10.1016/S0070-4571(08)70261-9

A. Steele, M.D. Fries, H.E.F. Amundsen, B.O. Mysen, M.L. Fogel, M. Schweizer, N.Z. Boctor, Comprehensive imaging and Raman spectroscopy of carbonate globules from Martian meteorite ALH 84001 and a terrestrial analogue from Svalbard. Meteorit. Planet. Sci. 42, 1549-1566 (2007)

R.E. Summons, J.P. Amend, D. Bish, R. Buick, G.D. Cody, D.J. Des Marais, G. Dromart, J.L. Eigenbrode, A.H. Knoll, D.Y. Sumner, Preservation of Martian organic and environmental records: final report of the Mars biosignature working group. Astrobiology 11, 157-181 (2011)

B. Sutter, A.C. McAdam, P.R. Mahaffy, D.W. Ming, K.S. Edgett, E.B. Rampe, J.L. Eigenbrode, H.B. Franz, C. Freissinet, J.P. Grotzinger, A. Steele, C.H. House, P.D. Archer, C.A. Malespin, R. Navarro-González, J.C. Stern, J.F. Bell, F.J. Calef, R. Gellert, D.P. Glavin, L.M. Thompson, A.S. Yen, Evolved gas analyses of sedimentary rocks and eolian sediment in Gale Crater, Mars: results of the Curiosity rover's sample analysis at Mars instrument from Yellowknife Bay to the Namib Dune. J. Geophys. Res., Planets 122, 2574-2609 (2017). https://doi.org/10.1002/2016JE005225

T.D. Swindle, A.H. Treiman, D.J. Lindstrom, M.K. Burkland, B.A. Cohen, J.A. Grier, B. Li, E.K. Olsen, Noble gases in iddingsite from the Lafayette meteorite: evidence for liquid water on Mars in the last few hundred million years. Meteorit. Planet. Sci. 35, 107-115 (2000)

K.L. Tanaka, The stratigraphy of Mars. J. Geophys. Res. 91, E139-E158 (1986)

K.L. Tanaka, J.A. Skinner Jr., J.M. Dohm, R.P. Irwin III, E.J. Kolb, C.M. Fortezzo, T. Platz, G.G. Michael, T.M. Hare, Geologic map of Mars. U.S.G.S. Scientific Investigations Map, \#3292 (2014). https://doi.org/ $10.3133 / \operatorname{sim} 3292$

P.M. Vasconcelos, K.A. Farley, C.A. Malespin, P. Mahaffy, D. Ming, S.M. McLennan, J.A. Hurowitz, M.S. Rice, Discordant K-Ar and young exposure dates for the Windjana sandstone, Kimberley, Gale Crater, Mars. J. Geophys. Res., Planets 121, 2176-2192 (2016). https://doi.org/10.1002/2016JE005017

M.A. Velbel, Crystallography on Mars - Curiosity's Bragging right. Am. Mineral. 103, 837-838 (2018). https://doi.org/10.2138/am-2018-6468

S.C. Werner, In situ calibration of the Martian cratering chronology. Meteorit. Planet. Sci. 54, 1182-1193 (2019). https://doi.org/10.1111/maps.13263

S.C. Werner, K.L. Tanaka, Redefinition of the crater-density and absolute-age boundaries for the chronostratigraphic system of Mars. Icarus 215, 603-607 (2011)

S.C. Werner, A. Ody, F. Poulet, The source crater of martian shergottite meteorites. Science 343, $1343-1346$ (2014). https://doi.org/10.1126/science.1247282

R. Wordsworth, The climate of early Mars. Annu. Rev. Earth Planet. Sci. 44, 381-408 (2016)

M.Y. Zolotov, M.V. Mironenko, Chemical models for martian weathering profiles: insights into formation of layered phyllosilicate and sulfate deposits. Icarus 275, 203-220 (2016) 